\title{
Antipsychotics and cognitive decline in Alzheimer's disease: the LASER-Alzheimer's disease longitudinal study
}

\author{
G Livingston, A E Walker, C L E Katona, C Cooper
}

See Editorial Commentary, p 2

J Neurol Neurosurg Psychiatry 2007;78:25-29. doi: 10.1136/jnnp.2006.094342

See end of article for authors' affiliations

......................

Correspondence to: $G$ Livingston, Department of Mental Health Sciences, University College London, Holborn Union Building, Archway Campus, Highgate Hill, London N19 5LW, UK; g.livingston@ucl.ac.uk

Received 30 March 2006

Revised 3 June 2006

Accepted 20 June 2006

Published Online First

26 June 2006

Objective: To investigate in a longitudinal cohort of people with Alzheimer's disease whether taking antipsychotics is associated with more rapid cognitive deterioration.

Method: From a sample of 224 people with Alzheimer's disease recruited as epidemiologically representative, those taking antipsychotic drugs for more than 6 months were compared with those who were not, in terms of change in three measures of cognition. The effects of potential mediators and confounders (demographic factors, neuropsychiatric symptoms, cognitive severity and cholinesterase inhibitors) were also examined.

Results: No significant difference was observed in cognitive decline between those taking antipsychotics (atypical or any) and others on any measure of cognition. The only predictor of more cognitive decline was greater baseline cognitive severity $(B=3.3,95 \%$ confidence interval 0.6 to $6.1, t=2.4, p<0.05)$. Although mortality was higher in those treated with antipsychotics, this reflected their greater age and severity of dementia. The results were the same when the whole cohort was included rather than the select group with potential to change who had been taking antipsychotics continuously.

Conclusions: In this, the first cohort study investigating the effects of atypical antipsychotics on cognitive outcome in Alzheimer's disease, those taking antipsychotics were no more likely to decline cognitively over 6 months. Although clinicians should remain cautious when prescribing antipsychotic drugs to people with Alzheimer's disease, any increase in cognitive deterioration is not of the magnitude previously reported. There is a need for cohort studies that follow up patients from first prescription in clinical practice for a period of months rather than weeks to determine "real-life" risks and benefits.

$\mathrm{N}$ europsychiatric symptoms are common (prevalence rate $\geqslant 60 \%$ ) and persistent in Alzheimer's disease particularly with increasing severity. ${ }^{1-3}$ They are associated with increased caregiver burden, ${ }^{4}$ institutionalisation, ${ }^{5}$ progression ${ }^{6}$ and care costs. ${ }^{1}$ Many people with Alzheimer's disease are treated with antipsychotics, often to ameliorate neuropsychiatric symptoms.

Typical and atypical antipsychotics block $\mathrm{D}_{2}$ and other receptors. Some atypical antipsychotics also blockade $5 \mathrm{HT}_{2}$, muscarinic or histaminic receptors. The $5 \mathrm{HT}_{2}$ and histamine receptor blockade may cause sedation and reduce alertness; thus the patient may do less well on cognitive testing, and muscarinic blockade can directly cause cognitive decline. Typical antipsychotics doubled the rate of cognitive decline in one cohort of people with dementia. ${ }^{7}$ This deterioration was not dose related, and may reflect more neuropsychiatric symptoms and hence antipsychotic drugs in those more likely to decline. A recent randomised controlled trial (RCT) in agitated patients with dementia in care homes found that the atypical quetiapine was associated with greater cognitive decline over 6 weeks than rivastigmine or placebo. ${ }^{8}$ This deterioration may, however, be explained by sedation" or the lower baseline cognition in the quetiapine group. ${ }^{10}$ Studies of the atypical olanzapine have reported mixed results, ranging from no effect ${ }^{11}$ to enhancing ${ }^{12}$ or worsening cognition. ${ }^{13}$ RCTs using risperidone for neuropsychiatric symptoms in dementia have, however, consistently found it to be effective without cognitive side effects. ${ }^{14-16}$

Two recent systematic reviews report only a modest improvement in neuropsychiatric symptoms from atypicals ${ }^{17}$ and none from typical antipsychotics. ${ }^{18}$ Typical antipsychotics have been associated with higher mortality than atypicals in older people with and without dementia. ${ }^{19}$ However, a recent meta-analysis of RCTs showing that in dementia, atypical antipsychotics are associated with a small increase in death rate has increased treatment concerns. ${ }^{20}$ Current international guidelines reflect this, suggesting that the use of atypicals should be restricted to licensed indications or severe, distressing symptoms. ${ }^{21} 22$

This is the first longitudinal cohort study to assess cognitive decline and mortality in people with Alzheimer's disease since atypical antipsychotic drugs became standard. It compares those taking and not taking antipsychotic drugs over a 6-month period shortly before the recent strictures on the use of atypicals. We examined whether other factors reported to relate to decline (demographics, baseline severity, neuropsychiatric symptoms or cholinesterase inhibitor use) could account for any of the differences found.

\section{Aims}

1. To investigate in a longitudinal cohort study of an epidemiologically representative sample of people with Alzheimer's disease whether those who take antipsychotics deteriorate to a greater extent cognitively than those who do not and whether any difference is dose related.

2. To investigate whether such deterioration could be mediated by demographic factors (age, sex and years of education); neuropsychiatric symptoms, (hallucinations, delusions, agitation, sleep disturbance and total neuropsychiatric symptom score), initial cognitive severity or taking cholinesterase inhibitors.

Abbreviations: ADAS-cog, Alzheimer's Disease Assessment ScaleCognitive Subscale; MMSE, Mini-Mental State Examination; NPI, Neuropsychiatric Inventory; RCT, randomised controlled trial; SIB, severe impairment battery 
3. To investigate whether mortality is higher in those taking antipsychotics and whether any relationship is mediated by demographic or clinical factors.

\section{Primary hypothesis}

People with Alzheimer's disease who take antipsychotics deteriorate considerably more in cognition over a 6-month period than those not taking antipsychotics.

\section{METHOD}

This is part of a larger naturalistic longitudinal cohort study of people with Alzheimer's disease and their caregivers from London and the south east region of England (the LASER-AD study). ${ }^{1}$ The relevant research ethics committees gave approval for the study.

Care recipients with a diagnosis of Alzheimer's disease ${ }^{23} 24$ and their caregivers were approached in inner-city, suburban, semirural and new town areas, through local services, voluntary sector and care home managers. Recruitment was designed to ensure that care recipients were epidemiologically representative of people with Alzheimer's disease in terms of sex, severity of illness and living settings. ${ }^{25}$ The present study reports baseline and 6-month follow-up data.

\section{Inclusion criteria}

- People for whom baseline and 6-month follow-up data were collected.

- Those whose severe impairment battery (SIB) scores had potential to improve or deteriorate; as in Ballard's study, ${ }^{8}$ those with a baseline SIB score $\leqslant 10$ and those with the maximum score (100) were excluded.

- Those who were consistently taking or not taking antipsychotics throughout the 6-month period.

\section{Interview}

Trained researchers from psychology, nursing and medicine conducted the interviews.

The following information was collected:

(a) Demographics: age, sex and years of education.

(b) Antipsychotic drugs: the name and dose of drugs was ascertained by asking what was taken and inspecting the tablets.

(c) The SIB assesses the cognitive abilities of more impaired patients with dementia. Potential scores range from 0 to $100^{26}$ and the SIB is sensitive to change. ${ }^{27}$

(d) The Mini-Mental State Examination (MMSE) measures cognitive impairment. The range is $0-30{ }^{28}$

(e) The Alzheimer's Disease Assessment Scale-Cognitive Subscale (ADAS-cog) assesses cognitive impairment. The range is $0-75$; higher scores indicate greater dysfunction. ${ }^{29}$

(f) The Neuropsychiatric Inventory (NPI) assesses 12 neuropsychiatric symptoms. ${ }^{30}$ Individual symptom scores range from $0-12$; symptom scores $\geqslant 4$ are regarded as clinically significant. ${ }^{1831}$ The sum of symptom scores constitutes a global score.

\section{Chlorpromazine equivalent calculation}

Table 1 gives the chlorpromazine equivalent calculation.

Doses of antipsychotic drugs at baseline and 6 months were converted into chlorpromazine equivalents. We used standard equivalents for haloperidol, risperidone and sulpiride, ${ }^{32}$ and for quetiapine and olanzapine. ${ }^{33}$
Table 1 Chlorpromazine equivalents (to $100 \mathrm{mg}$ ) for antipsychotic drugs based on the conversion guidelines of the British National Formulary ${ }^{32}$ for haloperidol, risperidone, and sulpiride, and based on Woods ${ }^{33}$ for quetiapine and olanzapine

\begin{tabular}{ll}
\hline Antipsychotics & Daily dose $(\mathrm{mg})$ \\
\hline Chlorpromazine & 100 \\
Haloperidol & $2-3$ \\
Olanzapine & 5 \\
Quetiapine & 75 \\
Risperidone & $0.5-1$ \\
Sulpiride & 200 \\
\hline
\end{tabular}

\section{Analysis}

Our primary hypothesis used the SIB because its lack of floor effect permits a more accurate measure of decline. We repeated the analysis using the MMSE and ADAS-cog. To control for floor effects in the respective analyses, we included those with an MMSE score of $>2$ and an ADAS-cog score of $<70$. We repeated the analysis, excluding those taking typical antipsychotics and including participants irrespective of floor and ceiling effects or the continuous use of antipsychotics. As our results for deterioration and the effects of postulated mediators were essentially the same, we report only the results for all antipsychotics, and the select group with potential to change and receiving continuous antipsychotics, and the SIB in detail.

We used Mann-Whitney U tests to compare cognitive change in those taking or not taking antipsychotic drugs throughout the 6-month period. We carried out step-wise linear regression analysis to identify independent predictors of differences in cognitive impairment scores. Step 1 incorporated age and severity at baseline (MMSE scores of >20 meaning mild, 10-20 moderate and $<10$ severe), sex and years of education; step 2 chlorpromazine equivalent dose of medication; step 3 total NPI score, NPI delusions, hallucinations, agitation and sleep scores at baseline; and step 4 prescription of cholinesterase inhibitors. We repeated the analysis dividing the scores for neuropsychiatric symptoms into clinically significant scores $(\geqslant 4)$ and nonsignificant scores. As most of those in the study were taking risperidone, we carried out a retrospective regression analysis considering the effects of atypicals other than risperidone. This did not change the results.

\section{Power calculation}

Our power calculation was based on the two studies showing a greater decline in cognition of the group taking antipsychotics versus a comparator. In the first, ${ }^{8}$ those on antipsychotics had a mean (standard deviation (SD)) SIB worsening of 11.3 points (15.6). In the placebo group, mean (SD) improvement was 3.3 (17.4). We had $97 \%$ power at a significance level of 0.01 to detect this difference in our study of 30 people taking and 132 not taking antipsychotics. Our second power calculation was based on data that found a decline of 20.7 points in the extended MMSE in those taking antipsychotics versus 9.3 in those not taking antipsychotics. ${ }^{7}$ We assumed SD $=15$. This gave $88 \%$ power at a significance level of 0.01 of finding a true difference in our study.

\section{RESULTS}

\section{Demographics}

In all, 224 people with Alzheimer's disease were interviewed at baseline. Of them, 184 potential participants remained in the study at 6 months ( 18 died, 8 withdrew and 14 were excluded because an antipsychotic drug was started or stopped). Eight $(44.4 \%)$ of those who had died and $46(22.3 \%)$ of those still 
Table 2 Differences at baseline between those included and those not included in this study

\begin{tabular}{|c|c|c|c|c|}
\hline Variables & Included ( $n=162$ ) & Not included $(n=62)$ & Statistics & $95 \% \mathrm{Cl} / \mathrm{IQR}$ \\
\hline $\begin{array}{l}\text { Sex, } n(\%) \text { female } \\
\text { Age, mean (SD) } \\
\text { SIB, median (range) } \\
\text { MMSE, mean (SD) } \\
\text { ADAS-cog- mean (SD) } \\
\text { NPI total median (range) } \\
\text { ADCS-ADL total median (range) } \\
\text { Taking antipsychotic } \\
\text { drugs, } n(\%)\end{array}$ & $\begin{array}{l}118(72.8) \\
80.8(7.5) \\
94(11-99) \\
16.8(6.9) \\
33.0(15.9) \\
13(0-79) \\
40.5(1-77) \\
30(18.5 \%)\end{array}$ & $\begin{array}{l}42(67.7) \\
81.7(7.3) \\
71(0-100)^{*} \\
9.3(9.3)^{*} \\
50.4(23.7)^{*} \\
18.5(0-69) \\
12.5(0-78)^{*} \\
24(38.7 \%)^{* *}\end{array}$ & $\begin{array}{l}\chi^{2}=0.6 \\
t=0.9 \\
U=2917 \\
t=5.7 \\
t=5.0 \\
U=4417 \\
U=2450 \\
\chi^{2}=10.0\end{array}$ & $\begin{array}{l}95 \% \mathrm{Cl} 0.7 \text { to } 2.4 \\
95 \% \mathrm{Cl}-1.2 \text { to } 3.2 \\
\text { IQR } 76-96 \\
95 \% \mathrm{Cl}-10.0 \text { to }-4.6 \\
95 \% \mathrm{Cl} 10.4 \text { to } 24.4 \\
\text { IQR } 7-25 \\
\text { IQR } 16-54.8 \\
95 \% \mathrm{Cl} 2.9 \text { to } 10.9\end{array}$ \\
\hline
\end{tabular}

alive were taking antipsychotics $\left(\mathrm{p}<0.05 ; \chi^{2}=4.4\right)$. Those who died were older and more severely cognitively impaired. When these confounders were incorporated into the logistic regression model, severity (odds ratio (OR) 2.38; 95\% confidence intervals (CI) 1.46 to $3.87 ; \mathrm{p}<0.001$ ) and age (OR $1.08 ; 95 \%$ CI 1.03 to 1.14; $\mathrm{p}=0.001$ ) independently predicted death, but taking an antipsychotic did not.

Of the 184 survivors, 162 fulfilled the inclusion criteria for the SIB analysis. Three did not complete the SIB; 19 had baseline floor or ceiling SIB scores (15 participants had a score $\leqslant 10,4$ participants had a score of 100$)$. Thirty of $162(18.5 \%)$ were taking antipsychotic drugs: $23(76.7 \%)$ risperidone, 3 ( $10 \%)$ olanzapine, $2(6.7 \%)$ quetiapine, $1(3.3 \%)$ chlorpromazine and 1 (3.3\%) sulpiride. The chlorpromazine equivalent range was 25-600 (mean 120.2) $\mathrm{mg}$ at baseline and 25-300 (mean 126.9) $\mathrm{mg}$ at 6 months.

Table 2 compares those included with the non-participants who were more cognitively impaired, more dependent and more likely to have been taking antipsychotics.

\section{MMSE and ADAS-cog}

Of 184 people, 163 fulfilled the inclusion criteria for the MMSE analysis ( 21 scored $\leqslant 2$ on baseline MMSE) and 149 fulfilled the inclusion criteria for the ADAS-cog analysis (12 with incomplete ADAS-cog at baseline, 3 at follow-up and 20 scored $\geqslant 70$ at baseline).

\section{Baseline comparison between the groups taking and not taking antipsychotics}

Table 3 compares the demography and morbidity of patients taking and not taking antipsychotic drugs.
Those taking antipsychotics had significantly lower baseline cognition, as measured using the SIB, and were less likely to be taking cholinesterase inhibitors (table 3 ). These findings remained the same for those taking atypical antipsychotic drugs and measuring cognition using either the MMSE or ADAS-Cog.

\section{Differences in cognitive deterioration between groups}

Table 4 gives the differences in rates of cognitive deterioration between those taking and not taking antipsychotic drugs.

We observed no significant differences in cognitive deterioration between those taking and not taking antipsychotics, using SIB, MMSE or ADAS-cog scores. Similarly, there was no significant correlation between antipsychotic dosages at baseline or 6 months (chlorpromazine equivalents) and cognitive deterioration in SIB (Spearman's correlation coefficient $\mathrm{r}=0.08, \mathrm{p}=0.31$ (baseline) and $\mathrm{r}=0.07, \mathrm{p}=0.37$ (6 months); MMSE $(\mathrm{r}=0.14, \mathrm{p}=0.09$; and $\mathrm{r}=0.40, \mathrm{p}=0.62$, respectively) or ADAS-cog $(\mathrm{r}=0.13, \mathrm{p}=0.11 ;$ and $\mathrm{r}=0.15, \mathrm{p}=0.07$, respectively).

\section{Differences in cognitive deterioration according to potential mediators and confounders}

The only factor significantly related to deterioration was baseline cognitive severity (Kruskal-Wallis $\chi^{2}=12.63, \mathrm{df}=2$, $\mathrm{p}<0.005$ ). Age, sex, education, cholinesterase inhibitors prescribed at baseline, baseline SIB scores, clinically significant score on NPI agitation, delusion, sleep, hallucinations and total NPI were not significantly related to deterioration in any of the three cognitive scores.

Table 3 Comparison of demography and morbidity between those taking and not taking antipsychotic drugs

\begin{tabular}{|c|c|c|c|c|}
\hline & Taking antipsychotics & Not taking antipsychotics & Statistics & $95 \% \mathrm{Cl} / \mathrm{IQR}$ \\
\hline Age, mean (SD) & $80.4(7.3)$ & $80.8(7.5)$ & $t=0.3$ & $95 \% \mathrm{Cl}-2.6$ to 3.4 \\
\hline Sex, $n(\%)$ female & $22(73.3)$ & $96(72.7)$ & $\chi^{2}=0.005$ & $95 \% \mathrm{Cl} 0.4$ to 2.5 \\
\hline SIB score at baseline, median (range) & $91(21-99)$ & $94(11-99)^{*}$ & $\tilde{U}=1405.5$ & IQR 87-97 \\
\hline MMSE score, median (range) & $15(3-25)$ & $19(4-29)^{* *}$ & $U=1154.5$ & IQR 13-22 \\
\hline ADAS-cog score, median (range) & $34.5(13-67)$ & $27.5(8-65)^{*}$ & $U=1160.5$ & IQR $20.25-40.75$ \\
\hline Years of education, mean (SD) & $9.2(2.2)$ & $9.5(1.5)$ & $t=0.7$ & $95 \% \mathrm{Cl}-0.7$ to 1.4 \\
\hline Total NPI score, median (range) & $11(0-79)$ & $14(0-69)$ & $U=1964.5$ & IQR 7-23 \\
\hline NPI delusions score, median (range) & $0(0-12)$ & $0(0-12)$ & $U=1930.5$ & IQR 0 to 1.3 \\
\hline NPI hallucinations score, median (range) & $0(0-4)$ & $0(0-12)$ & $U=1954.0$ & IQR O-0 \\
\hline NPI agitation score, median (range) & $1(0-12)$ & $0(0-12)$ & $U=1709.0$ & IQR 0-2 \\
\hline NPI sleep disturbance score, median (range) & $0(0-12)$ & $0(0-12)$ & $U=1899.5$ & IQR 0-2 \\
\hline Cholinesterase inhibitors prescribed, $\mathrm{n}(\%)$ & $12(40)$ & $92(69.7)^{* * *}$ & $\chi^{2}=9.4$ & $95 \% \mathrm{Cl} 0.1$ to 0.7 \\
\hline
\end{tabular}

ADAS-cog, Alzheimer's Disease Assessment Scale-Cognitive Subscale; IQR, interquartile range; MMSE, Mini-Mental State Examination; NPI, Neuropsychiatric Inventory; SIB, severe impairment battery; $t, T$ test; $U$, Mann-Whitney U test. ${ }^{*} \mathrm{p}<0.05$. 
Table 4 Differences in rates of cognitive deterioration between those taking and not taking antipsychotic drugs

\begin{tabular}{|c|c|c|c|c|c|}
\hline \multirow[b]{2}{*}{ Cognitive test } & \multicolumn{2}{|l|}{ Deterioration } & \multirow[b]{2}{*}{ Statistics } & \multirow[b]{2}{*}{$95 \% \mathrm{Cl} / \mathrm{IQR}$} & \multirow[b]{2}{*}{ p Value } \\
\hline & Taking antipsychotics & $\begin{array}{l}\text { Not taking } \\
\text { antipsychotics }\end{array}$ & & & \\
\hline SIB, median (range) & $3.0(-34$ to 32$)$ & $0(-22$ to 87$)$ & $U=1712.0$ & IQR-3-4 & 0.247 \\
\hline MMSE, mean (SD) & $1.0(3.1)$ & $0.9(3.6)$ & $t=-0.2$ & $95 \% \mathrm{Cl}-1.4$ to 1.2 & 0.878 \\
\hline ADAS-cog, mean (SD) & $2.8(8.0)$ & $1.4(8.1)$ & $t=-0.8$ & $95 \% \mathrm{Cl}-5.0$ to 2.1 & 0.421 \\
\hline
\end{tabular}

ADAS-cog, Alzheimer's Disease Assessment Scale-Cognitive Subscale; IQR, interquartile range; MMSE, Mini-Mental State Examination; SIB, severe impairment

battery; $t$, T test; $U$, Mann-Whitney $U$ test.

\section{Independent predictors of differences in cognition in stepwise linear regression}

In step 1 , deterioration in SIB scores was predicted by increasing cognitive severity $(\mathrm{B}=3.3,95 \%$ CI 0.6 to 6.1 , $\mathrm{t}=2.4, \mathrm{p}<0.05)$. In steps 2,3 , and 4 there was no difference in the model. If prescription of antipsychotics or prescription of atypicals only was substituted for chlorpromazine equivalents, the same significant predictors emerged.

Similarly, decline in the other measures of cognition (MMSE and ADAS-cog) was not predicted by antipsychotic drugs (all, atypicals only or atypicals other than risperidone), dosage or any of the potential mediators or confounders identified other than cognitive severity.

\section{DISCUSSION}

People who were taking any or only atypical antipsychotics were no more likely to decline cognitively than those who were not. An increased dose did not correlate with greater cognitive decline, suggesting no causative relationship between cognitive decline and antipsychotic prescription. We used three validated measures of cognition, all of which showed the same result and controlled for potential confounders. In addition, the results were the same when we included the whole cohort rather than the select group of patients with potential to change who had been taking antipsychotics continuously. We can therefore state confidently that any difference in cognitive deterioration over 6 months was not of the magnitude reported by earlier studies. ${ }^{78}$ Although taking antipsychotics was associated with increased mortality, this was accounted for by greater age and cognitive impairment.

A strength of our study is that those testing cognition were not aware of the drugs prescribed, avoiding interviewer bias. It is limited by the two groups (those taking and not taking antipsychotics over the 6-month period) differing significantly in baseline cognition and in prescription of cholinesterase inhibitors, reflecting its naturalistic nature. Similarly, we do not know the duration of prescription before the 6-month period of taking cholinesterase inhibitors. Thus we cannot comment whether this may have had an effect. This means, however, that those taking antipsychotics were more likely to decline, and this strengthens our negative finding. As our study was naturalistic rather than an RCT, those taking antipsychotics may have been inherently less likely to decline than those not taking antipsychotics. This is improbable as antipsychotics are usually prescribed for those who are relatively unwell. We found no significant difference in neuropsychiatric symptoms at baseline between those who were treated and those who were not treated with antipsychotics, perhaps because the antipsychotics had started to be effective.

Our findings may differ because in previous studies the participants were taking typicals, ${ }^{7}$ had just started taking antipsychotics, or had greater cognitive severity than controls. ${ }^{8}$ It is also noteworthy that most of our participants were taking risperidone, a drug that seems from RCT data to be relatively unassociated with cognitive deterioration, ${ }^{14-16}$ but we found no difference in cognitive deterioration between those taking risperidone and those taking other antipsychotics. Our data could not rule out the possibility that atypicals cause an acute deterioration in cognition, consistent with the immediate sedative effect of antipsychotics, which improves with time. Possibly, those experiencing pronounced side effects from antipsychotics are more likely to have them discontinued than those within an RCT. This is one of the advantages of a real-life follow-up.

We conclude that although clinicians should continue to monitor people with Alzheimer's disease carefully when prescribing atypicals, there is a need for cohort studies that follow up patients from first prescription in clinical practice for a period of months rather than weeks to clarify risks and benefits of the antipsychotic drugs outside of clinical trials.

\section{ACKNOWLEDGEMENTS}

We thank the people with Alzheimer's disease and their families, friends and other carers who participated in the study. We also thank the consultant psychiatrists, community mental health teams and staff of the nursing and residential homes who provided us with support and help.

\section{Authors' affiliations}

G Livingston, A E Walker, C Cooper, Department of Mental Health Sciences, University College London, London, UK

C L E Katona, Kent Institute of Medicine and Health Sciences, University of Kent, Canterbury, Kent, UK

Funding: We would like to thank Lundbeck SA for funding the data collection for the whole project. Lundbeck has neither seen nor has any knowledge of this paper.

Competing interests: None.

This project has been reviewed and approved by the appropriate ethics committees. The lead ethics committee was Camden and Islington community research ethics committee. It was also approved by the Barnet, Haringey and Enfield, and West Essex committees.

\section{REFERENCES}

1 Ryu SH, Katona C, Rive B, et al. Persistence of and changes in neuropsychiatric symptoms in Alzheimer's disease over 6 months: the LASER-AD study. Am J Geriatr Psychiatry 2005; 13:11976-983.

2 Lyketsos CG, Steinberg M, Tschanz JT, et al. Mental and behavioral disturbances in dementia: findings from the Cache County Study on memory in Aging Am J Psychiatry. 2000;157: 5 708-714)

3 Hope T, Keene J, Fairburn CG, et al. Natural history of behavioural changes and psychiatric symptoms in Alzheimer's disease: a longitudinal study. Br J Psychiatry $1999 ; 174: 39-44$

4 Coen RF, Swanwick GR, O'Boyle CA, et al. Behaviour disturbance and other predictors of carer burden in Alzheimer's disease. Int J Geriatr Psychiatry 1997:12:331-6.

5 O'Donnell BF, Drachman DA, Barned HJ, et al. Incontinence and troublesome behaviors predict institutionalisation in dementia. J Geriatr Psychiatry Neurol 1992;5:45-52.

6 Paulsen JS, Salmon DP, Thai $\amalg$, et al. Incidence of and risk factors for hallucinations and delusions in patients with problable AD. Neurology 2000;54:1965-71

7 McShane R, Keene J, Gedling K, et al. Do neuroleptic drugs hasten cognitive decline in dementia? Prospective study with necropsy follow up. BMJ $1997 ; 314: 266$ 
8 Ballard C, Margallo-Lana M, Juszczak E, et al. Quetiapine and rivastigmine and cognitive decline in Alzheimer's disease: randomised double blind placebo controlled trial. BMJ 2005;330:874.

9 Turner EH. Cognitive changes could be explained by reversible acute sedative effects. BMJ 2005 http://bmi.bmijournals.com/cgi/eletters/330/7496/ 874\#103545 (accessed 8 September 2006).

10 Kaimal AB, Nair UV. The cognitive decline associated with quetiapine in Alzheimer's disease. BMJ 2005 http://bmj.bmjjournals.com/cgi/eletters/330/ 7496/874\# 103545 (accessed 8 September 2006).

11 Street JS, Clark WS, Kadam DL, et al. Long term efficacy of olanzepine in the control of psychotic and behavioral symptoms in nursing home patients with Alzheimer's dementia. Int J Geriatr Psychiatry 2001;16:S62-70.

12 De Deyn PP, Carrasco MM, Deberdt W, et al. Olanzapine versus placebo in the treatment of psychosis with or without associated behavioral disturbances in patients with Alzheimer's disease. Int J Geriatr Psychiatry 2004;19:115-26.

13 Kennedy J, Debert W, Siegal A, et al. Olanzapine does not enhance cognition in non-agitated and non-psychotic patients with mild to moderate Alzheimer's disease. Int J Geriatr Psychiatry 2005;20:1020-7.

14 Brodaty H, Ames D, Snowdon J, et al. Risperidone for psychosis of Alzheimer's disease and mixed dementia: results of a double-blind, placebo-controlled trial. Int J Geriatr Psychiatry 2005;20:1153-7.

15 Brodaty H, Ames D, Snowdon J, et al. A randomized placebo-controlled trial of risperidone for the treatment of aggression, agitation, and psychosis of dementia. J Clin Psychiatry 2003:64:134-43.

16 De Deyn P, Katz I. Control of aggression and agitation in patients with dementia: efficacy and safety of risperidone. Int J Geriatr Psychiatry 2000;15:S14-22.

17 Sink KM, Holden KF, Yaffe K. Drugs minimally effective for neuropsychiatric symptoms of dementia. J Fam Pract 2005;54:401-9.

18 Lee PE, Gill SS, Freedman M, et al. Atypical antipsychotics in the treatment of behavioural and psychological symptoms of dementia: systematic review. BMJ 2004;329:75-8.

19 Wang PS, Schneeweiss S, Avorn J, et al. Risk of death in elderly users of conventional vs. atypical antipsychotic medications. N Engl J Med 2005;353:2335-41.
20 Schneider LS, Dagerman KS, Insel P. Risk of death with atypical antipsychotic drug treatment for dementia: meta-analysis of randomized placebo-controlled trials. JAMA 2005;294:1934-43.

21 Rabins PV, Lyketsos CG. Antipsychotic drugs in dementia: what should be made of the risks? JAMA 2005:294:1963-5.

22 http://www.rcpsych.ac.uk/pdf/Atypicalguidance.pdf (accessed 17 Jan 2006).

23 American Psychiatric Association (APA). Diagnostic and statistical manual of mental disorders, 4th edn. Washington, DC: APA, 1994.

24 McKhann G, Drachman D, Folstein M, et al. Clinical diagnosis of Alzheimer's disease: report of the NINCDS-ADRDA work group under the auspices of department of health and human services task force on Alzheimer's disease. Neurology 1984;34:939-44.

25 Fratiglioni L. Epidemiology. In: Wimo A, Jonsson B, Karlsson G, Winblad B, eds. Health economics of dementia. New York: John Wiley \& Sons, 1998:13-31.

26 Saxton J, McGonigle-Gibson K, Swihart A, et al. Assessment of the severely impaired patient: description and validation of a new neuropsychological test battery. Psychol Assess 1990;2:298-303.

27 Schmitt FA, Ashford W, Ernesto C, et al. The severe impairment battery: concurrent validity and the assessment of longitudinal change in Alzheimer's disease. The Alzheimer's Disease Cooperative Study. Alzheimer Dis Assoc Disord 1997; 11:S51-6.

28 Folstein MF, Folstein SE, McHugh PR. Mini-mental state: a practical method for grading the state of patients for the clinician. J Psychiatr Res 1975;12:198.

29 Rosen WG, Mohs RC, Davis KL. A new rating scale for Alzheimer's disease. Am J Psychiatry 1984;141:1356-64.

30 Cummings JL, Mega M, Gray K, et al. The neuropsychiatric inventory: comprehensive assessment of psychopathology in dementia. Neurology 1994:44:2308-2314.

31 Schneider LS, Tariot PN, Lyketsos CG, et al. National Institute of Mental Health Clinical Antipsychotic Trials of Intervention Effectiveness (CATIE): Alzheimer disease trial methology. Am J Geriatr Psychiatry 2001;9:346-60.

32 Joint Formulary Committee. British National Formulary. London: British Medical Association and Royal Pharmaceutical Society of Great Britain, 2005:175.

33 Woods SW. Chlorpromazine equivalent doses for the newer atypical antipsychotics. J Clin Psychiatry. 2003;64: 6, 663-7).

\section{bmjupdates+}

bmiupdates+ is a unique and free alerting service, designed to keep you up to date with the medical literature that is truly important to your practice.

bmjupdates+ will alert you to important new research and will provide you with the best new evidence concerning important advances in health care, tailored to your medical interests and time demands.

Where does the information come from?

bmjupdates+ applies an expert critical appraisal filter to over 100 top medical journals A panel of over 2000 physicians find the few 'must read' studies for each area of clinical interest

Sign up to receive your tailored email alerts, searching access and more...

www.bmjupdates.com 